\title{
Mechanism of mechanical quenching and mechanoluminescence in phosphorescent $\mathrm{CaZnOS}: \mathrm{Cu}$
}

\author{
Dong $\mathrm{Tu}^{1,2}$, Chao-Nan $\mathrm{Xu}^{1,2,3}$, Yuki Fujio ${ }^{1}$ and Akihito Yoshida ${ }^{1}$ \\ This article reports a new phosphorescent material, $\mathrm{CaZnOS}: \mathrm{Cu}$, that exhibits two types of mechano-optical conversion: mechanical \\ quenching and mechanoluminescence. An intense mechanical quenching of phosphorescence corresponding to mechanical stimuli \\ can be achieved in CaZnOS:Cu within a short decay time period. Over time, it gradually changes to mechanoluminescence when a \\ mechanical load is applied. We propose that the mechanical quenching and mechanoluminescence arise from the different roles of \\ shallow and deep traps in $\mathrm{CaZnOS}: \mathrm{Cu}$. CaZnOS:Cu has promising applications in monitoring mechanical stress in industrial plants, \\ structures, and living bodies.
}

Light: Science \& Applications (2015) 4, e356; doi:10.1038/lsa.2015.129; published online 20 November 2015

Keywords: mechanical quenching; mechanoluminescence; phosphorescence; traps

\section{INTRODUCTION}

Adjusting and controlling the optical properties of materials by altering environmental factors are important in the development of various applications in sensing, memory, detection, and display devices ${ }^{1-6}$. Mechanical stress is the most common external stimulus, and thus materials that exhibit mechano-optical conversion are promising for practical applications in science and engineering ${ }^{7-12}$.

Mechanoluminescent (ML) materials emit light when mechanical energy is applied and are effective for mechano-optical conver$\operatorname{sion}^{1,9,13,14}$. Therefore, ML materials have been used as optical sensors for monitoring changes in mechanical stress. Many ML materials with different luminescent colors, such as $\mathrm{ZnS}: \mathrm{Cu}^{2+15,16}, \mathrm{CaAl}_{2} \mathrm{Si}_{2} \mathrm{O}_{8}$ : $\mathrm{Eu}^{2+17}, \mathrm{SrMg}_{2}\left(\mathrm{PO}_{4}\right)_{2}: \mathrm{Eu}^{2+}$ (blue ${ }^{18}, \mathrm{SrAl}_{2} \mathrm{O}_{4}: \mathrm{Eu}^{2+1,6,19,20}, \mathrm{BaSi}_{2} \mathrm{O}_{2} \mathrm{~N}_{2}$ : $\mathrm{Eu}^{2+}$ (green) ${ }^{21,22}, \mathrm{CaZnOS}: \mathrm{Mn}^{2+23,24}$, and $\mathrm{Sr}_{\mathrm{n}+1} \mathrm{Sn}_{\mathrm{n}} \mathrm{O}_{3 \mathrm{n}+1}: \mathrm{Sm}^{3+}$ $(\text { red })^{25}$, have been explored. Recently, our group has discovered another type of mechano-optical conversion, which is referred to as mechanical quenching $(\mathrm{MQ})^{26}$. In contrast to $\mathrm{ML}, \mathrm{MQ}$ is the quenching of phosphorescence intensity by using mechanical stimuli. Previously, we reported that CaZnOS:Cu exhibited MQ under applied mechanical stress. However, to understand the MQ process and mechanism further and use it for practical applications, the crystal structure, phosphorescence properties, and MQ properties of CaZnOS:Cu must be determined.

Here, we carry out further study on MQ in a phosphorescent material, CaZnOS:Cu. We examine the change in crystal structure that is caused by changing the $\mathrm{Cu}$ concentration, the phosphorescence properties, and the MQ mechanism. We find that CaZnOS:Cu exhibits a variety of mechano-optical conversions depending on the experimental conditions.

\section{MATERIALS AND METHODS}

CaZnOS:Cu was synthesized by a solid-state reaction method. Highpurity $\mathrm{CaCO}_{3}$ (50 mol\% excess) and appropriate amounts of $\mathrm{ZnS}$ and $\mathrm{Cu}_{2} \mathrm{O}$ were weighed and ground in an agate mortar with ethanol and then sintered under an air flow at $1100{ }^{\circ} \mathrm{C}$ for $5 \mathrm{~h}$. The excess calcium compounds were removed from the sample by washing with an aqueous solution of acetic acid. After filtration and drying, CaZnOS: $\mathrm{Cu}$ was ground again and then pulverized for measurement.

The crystalline phase of CaZnOS:Cu was characterized by using X-ray powder diffraction (XRD; RINT-2000, Rigaku Co., Tokyo, Japan) with $\mathrm{CuK} \alpha$ radiation ( $1.5418 \AA$; cathode voltage, $40 \mathrm{kV}$; current, $40 \mathrm{~mA}$ ) at room temperature. As reported previously, CaZnOS has an unusual structure with the space group $\mathrm{PG}_{3} m c$, which is a noncentrosymmetric structure. It is composed of layers of tetrahedral $\mathrm{ZnS}_{3} \mathrm{O}$ aligned with $\mathrm{Zn}-\mathrm{O}$ bond vectors parallel to the $c$-axis and linked to all of their S-containing vertices, which results in ${ }_{\infty}\left[\mathrm{ZnS}_{3 / 3} \mathrm{O}\right]^{2-}$ layers. Because of this special structure, CaZnOS also exhibits piezoelectric properties $^{27}$. The XRD data were analyzed using the Rietveld method, and RIETAN-FP was used to estimate the unit cell parameters. The photoluminescence (PL), phosphorescence spectra, and decay curve of the materials were recorded using a fluorescence spectrometer (FP-6600, JASCO Co., Tokyo, Japan) equipped with a $150 \mathrm{~W}$ Xe lamp at room temperature. The PL quantum yields of $\mathrm{CaZnOS:Cu}$ were also calculated which were higher than other well-known Cu-doped materials, such as $\mathrm{ZnS}: \mathrm{Cu}$ and $\mathrm{ZnSe:Cu}$ (Supplementary Fig. S1). The thermoluminescence was measured by combining the fluorescence spectrometer with a lab-built temperature control unit. The samples were first exposed to UV light ( $365 \mathrm{~nm})$ for $1 \mathrm{~min}$; after a pause with different decay times (3, $10,20 \mathrm{~min}$ and $1,3,12 \mathrm{~h}$ ), the thermoluminescence was measured at 472 $\mathrm{nm}$ over $25-250^{\circ} \mathrm{C}$. The decay time was defined as the time between the end of the excitation and the moment when the external stimulus (load or heat) was applied to the samples.

${ }^{1}$ National Institute of Advanced Industrial Science and Technology (AIST), Saga 841-0052, Japan; ${ }^{2}$ Interdisciplinary Graduate School of Engineering Sciences, Kyushu University, Fukuoka 816-8580, Japan and ${ }^{3}$ International Institute for Carbon-Neutral Energy Research (WPI-I²CNER), Kyushu University, Fukuoka 819-0395, Japan 


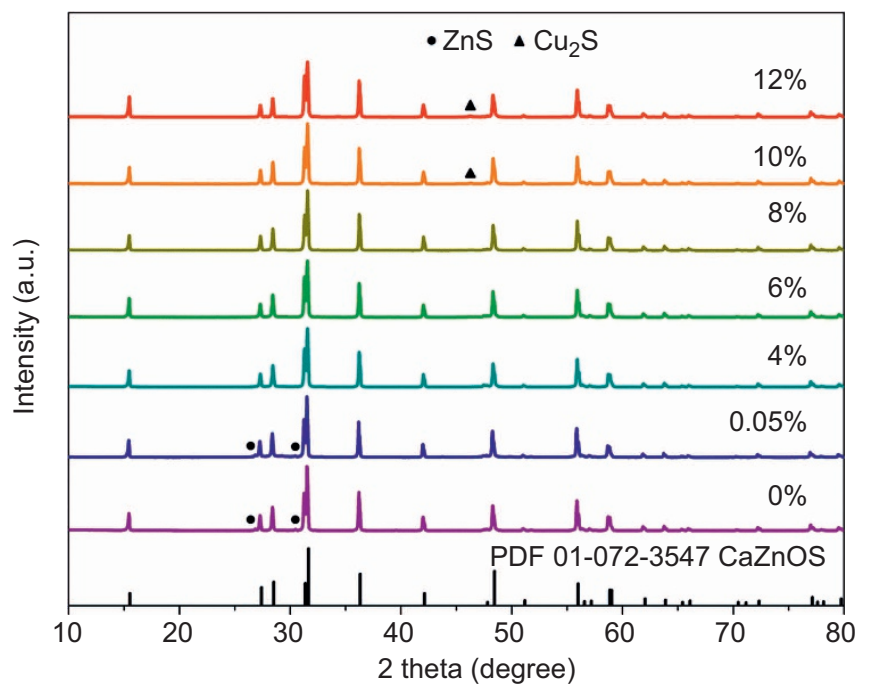

Figure 1 XRD patterns of CaZnOS:Cu with different Cu concentrations.

For evaluating the MQ properties of the samples, composite pellets (diameter, $25 \mathrm{~mm}$; thickness, $15 \mathrm{~mm}$ ) were prepared by mixing the CaZnOS:Cu powders with an optical epoxy resin. The pellet was exposed to UV light $(365 \mathrm{~nm})$ for $1 \mathrm{~min}$; after a pause with different decay times (3, $20 \mathrm{~min}$ and 1, 3, $12 \mathrm{~h}$ ), the phosphorescence intensity under the load was measured with a lab-made system comprising a universal testing machine (RTC-1310A, Orientec Corp., Tokyo, Japan) and a photon-counting system, which consisted of a photomultiplier tube (R585S, Hamamatsu Photonics, Hamamatsu, Japan), a photon counter (C5410-51, Hamamatsu Photonics), and a computer, as previously reported ${ }^{26}$. The testing machine applied a mechanical load, and the photon-counting system detected the phosphorescence intensity. Photographs of the MQ were recorded by a charge-coupled device camera. All of the MQ intensities $\left(I_{\mathrm{MQ}}\right)$ were calculated under the load using Equation (1):

$$
I_{\mathrm{MQ}}(\mathrm{load})=I(\mathrm{load})-I(0)
$$

Here, $I$ (load) is the phosphorescence intensity under the applied load, and $I(0)$ is the phosphorescence intensity under zero load.

\section{RESULTS AND DISCUSSION}

Figure 1 shows the powder XRD patterns of CaZnOS:Cu with different $\mathrm{Cu}$ concentrations. All of the patterns were identical to the Powder Diffraction File standard for the hexagonal phase of CaZnOS (JCPDS 01-072-3547), although a very small amount of $\mathrm{ZnS}$ impurity was observed for $\mathrm{Cu}$ concentrations of $0 \%$ and $0.05 \%$. When the $\mathrm{Cu}$ concentration increased to $10 \%$ and $12 \%$, another impurity phase of $\mathrm{Cu}_{2} \mathrm{~S}$ appeared, which indicated that increasing the $\mathrm{Cu}$ concentration further was not helpful for synthesizing the pure CaZnOS:Cu phase. In addition, no obvious peak shift was found in these XRD patterns, which indicated that $\mathrm{Cu}$-doping induced little change in the crystal structure of CaZnOS:Cu.

To determine the crystal structure of the obtained samples, Rietveld structure refinement was performed using the powder diffraction data. Figure 2 plots the lattice parameters (from the Rietveld refinement) as a function of $\mathrm{Cu}$ concentration. As the $\mathrm{Cu}$ concentration increased from $0 \%$ to $12 \%$, the variation in the $a$ axis (ranging from 3.7619 to $3.7634 \AA$ ), $c$-axis (ranging from 11.4082 to $11.4119 \AA$ ), and lattice volume, $V$ (ranging from 139.8192 to $139.9754 \AA^{3}$ ) remained stable in a narrow range because $\mathrm{Zn}^{2+}(0.60 \AA, \mathrm{CN}=4)^{28,29}$ was substituted with $\mathrm{Cu}^{+}(0.60 \AA, \mathrm{CN}=4)^{30,31}$, which has a similar ionic radius. X-ray photoelectron spectroscopy showed that the CaZnOS was doped with $\mathrm{Cu}^{+}$, which also confirmed that the $\mathrm{Cu}^{+}$was doped into the $\mathrm{Zn}^{2+}$ site of the CaZnOS crystal structure; it was difficult to

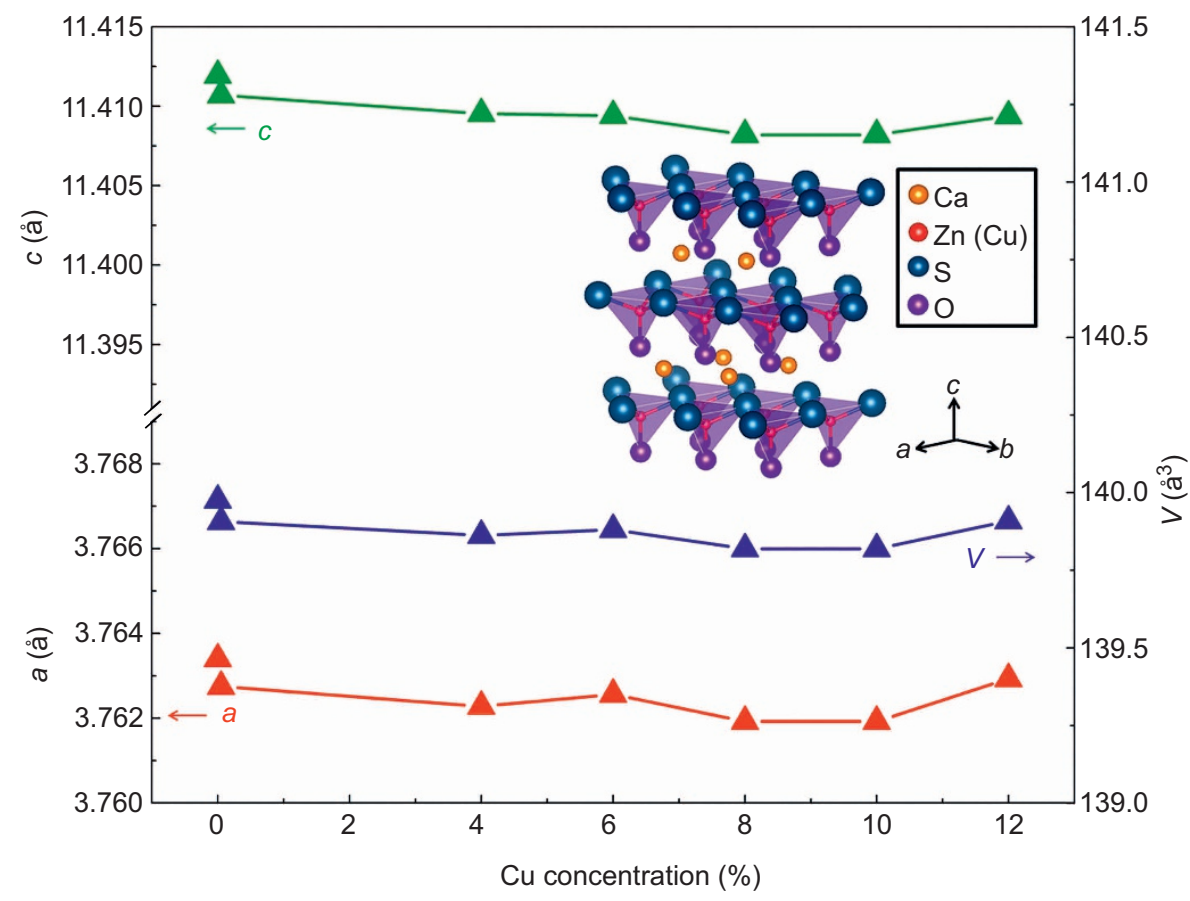

Figure 2 Characterization of CaZnOS:Cu lattice constants determined from the Rietveld refinement. A schematic of the crystal structure of CaZnOS:Cu is shown in the inset. 


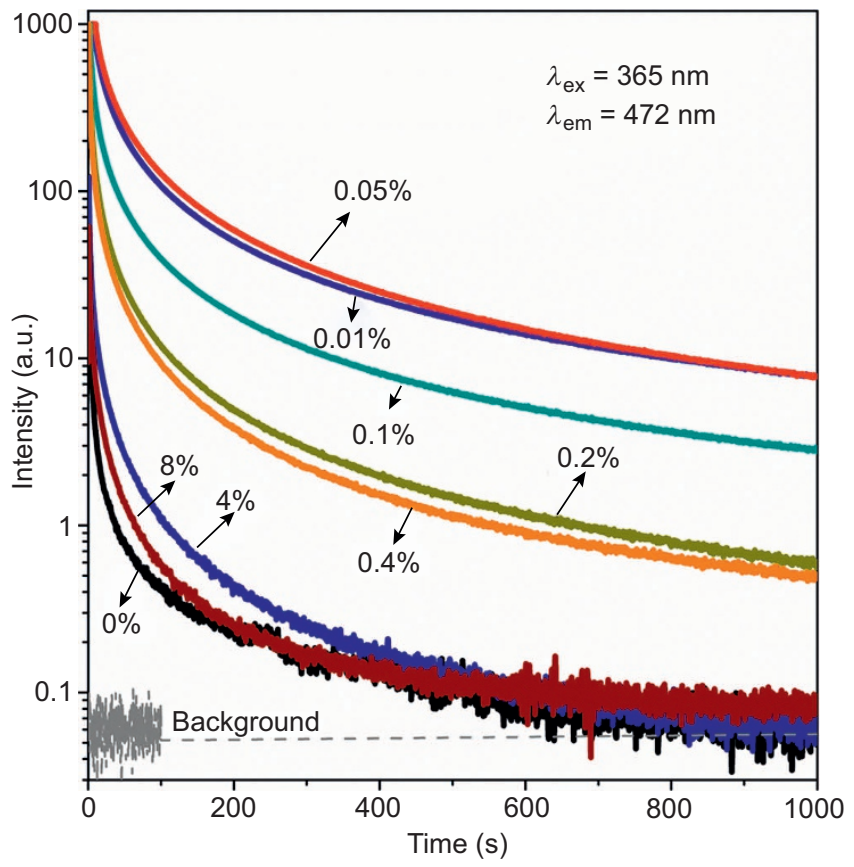

Figure 3 Phosphorescence intensity as a function of time under $365 \mathrm{~nm}$ irradiation, recorded at $472 \mathrm{~nm}$. The gray dashed line represents the background for this experiment.

substitute $\mathrm{Cu}^{+}$into the $\mathrm{Ca}^{2+}$ site because of the large radius mismatch of $\mathrm{Ca}^{2+}(1.00 \AA, \mathrm{CN}=6)^{32}$. According to the XRD refinement results, CaZnOS:Cu maintained its original crystal structure, even at a $\mathrm{Cu}$ concentration of $12 \%$, and it possessed a noncentrosymmetric layered structure with a space group of $\mathrm{P}_{3} m c$ (inset in Figure 2).

The phosphorescence decay curves of CaZnOS:Cu samples with different $\mathrm{Cu}$ concentrations under $365 \mathrm{~nm}$ UV excitation are shown in Figure 3. All of the samples exhibited phosphorescence after UV irradiation, and the phosphorescence intensity was remarkably high for the low $\mathrm{Cu}$ concentration $(0.01 \%, 0.05 \%$, and $0.1 \%)$ compounds. The $0.05 \%$ Cu-doped CaZnOS sample exhibited the highest phosphorescence intensity. Although a small amount of impurities remained, we focused on the composition of $0.05 \% \mathrm{Cu}$-doped CaZnOS (referred to hereafter as CZOSC) as a representative example for studying the optical properties of these compounds.

Figure 4a shows the normalized phosphorescence spectra of the CZOSC sample acquired at different times after the UV irradiation $(\lambda=365 \mathrm{~nm})$. The phosphorescence spectra were similar to the PL emission spectra (not shown in figure), but the phosphorescence peaks shifted to a longer wavelength over time, which indicated that the luminescence of CaZnOS:Cu resulted from donor-acceptor (DA) recombination ${ }^{33}$. To evaluate the effectiveness of different excitation wavelengths (energies) for the phosphorescence, we measured the phosphorescence intensity at $472 \mathrm{~nm}$ after excitation with monochromatic light with wavelengths between 200 and $450 \mathrm{~nm}$ in 5-nm steps. The phosphorescence intensity was recorded $10 \mathrm{~s}$ after the excitation was stopped and is denoted as $I_{10 \mathrm{~s}}$. Figure $4 \mathrm{~b}$ plots the phosphorescence intensity, $I_{10 \mathrm{~s}}$, monitored at $472 \mathrm{~nm}$ as a function of the excitation wavelength. The usual PL excitation spectrum monitored at $472 \mathrm{~nm}$ is also given in Figure $4 \mathrm{~b}$ for comparison. The shape of these two spectra was different; the excitation around $365 \mathrm{~nm}$ was more effective for phosphorescence than was the PL excitation peak at 335 $\mathrm{nm}$. Therefore, we chose $365 \mathrm{~nm}$ UV light as the phosphorescent excitation wavelength in the following study.
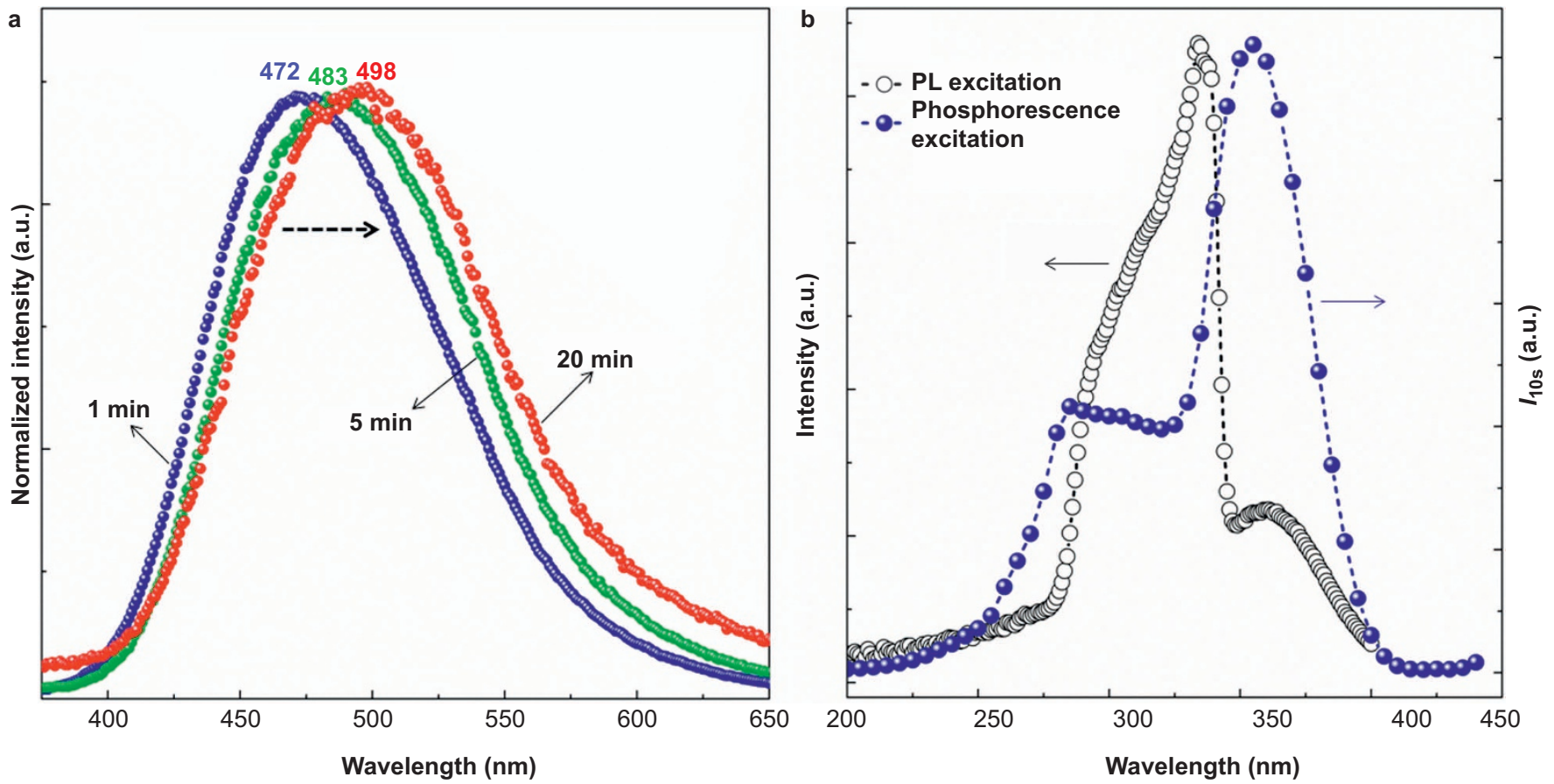

Figure 4 (a) Phosphorescence spectra recorded 1, 5, and 20 min after stopping the irradiation. (b) Phosphorescence excitation spectrum obtained by plotting the phosphorescence intensity $\left(I_{10 \mathrm{~s}}\right)$ monitored at $472 \mathrm{~nm}$ as a function of the excitation wavelength from 200 to $450 \mathrm{~nm}$. The sample was irradiated for $1 \mathrm{~min}$ at each wavelength. The excitation spectrum monitored at $472 \mathrm{~nm}$ (black open circle) is shown for comparison. 

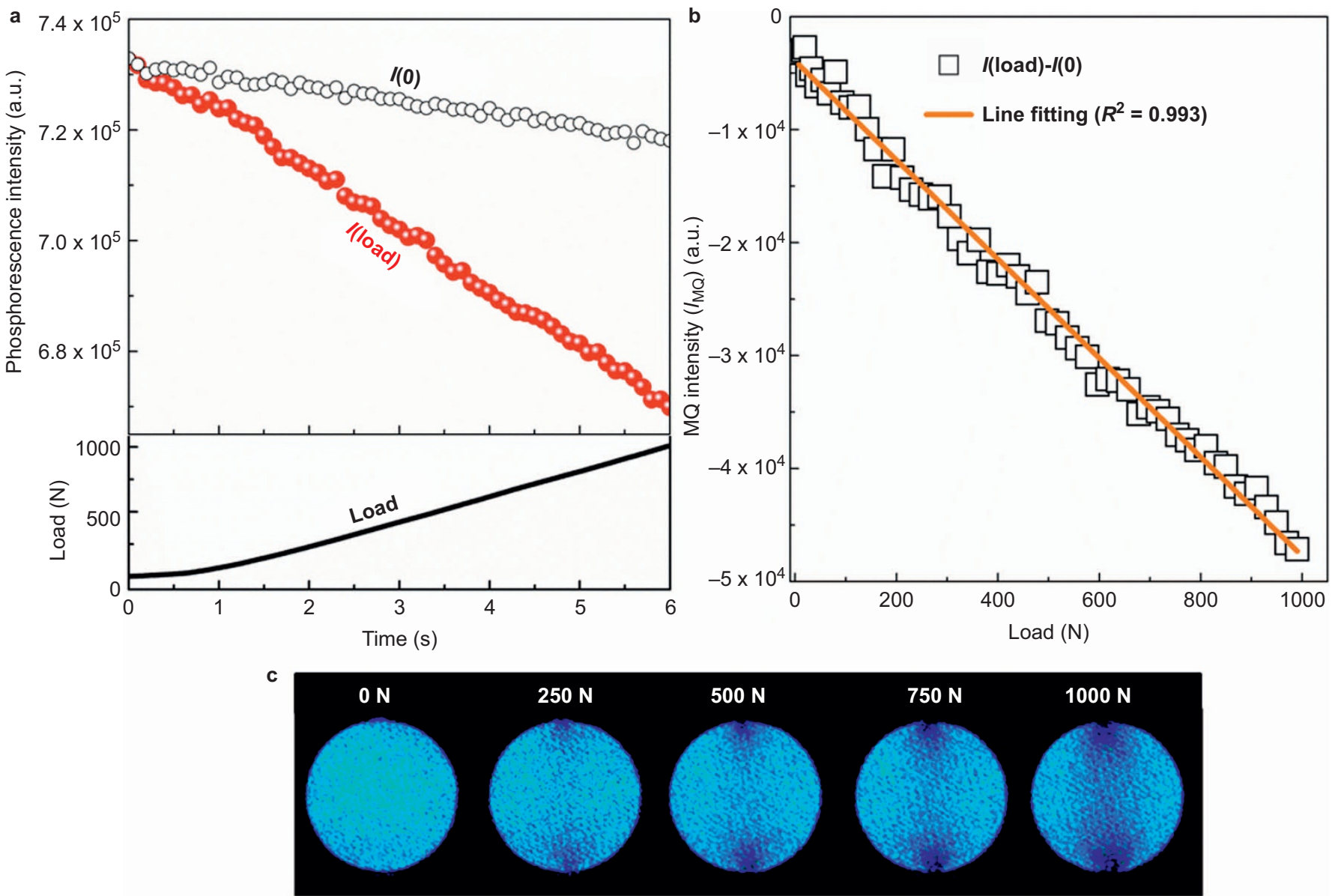

Figure 5 (a) Phosphorescence curve $I(\mathrm{load})$ and $I(0)$ for CZOSC monitored at $472 \mathrm{~nm}$ when a load up to $1000 \mathrm{~N}$ was applied over time; the load curve for $/($ load) is shown at the bottom; (b) MQ response for CZOSC; (c) MQ photographs of the CZOSC pellet at various loads from 0 to $1000 \mathrm{~N}$ in a single load process.

Figure 5a shows the phosphorescence intensity of the CZOSC pellet under a compressive load $I$ (load) and zero load $I(0)$. The phosphorescence intensity $I(0)$ decayed slowly. However, as the applied load increased from 0 to $1000 \mathrm{~N}$ (bottom in Figure 5a), the $I$ (load) showed phosphorescence quenching in response to the applied load. Figure $5 \mathrm{~b}$ shows the MQ response for the CZOSC with a compressive load of up to $1000 \mathrm{~N}$. The calculated MQ intensity $\left(I_{\mathrm{MQ}}\right)$ of the CZOSC pellet immediately decreased linearly when a load was applied to the pellet. The MQ intensity was proportional to the applied load, as described by Equation (2):

$$
I_{\mathrm{MQ}}=k \sigma_{\mathrm{eq}}
$$

Here, $\sigma_{\mathrm{eq}}$ is the equivalent stress, and $k$ is a constant. As shown in Figure $5 c$, when a compressive load is applied to the pellet, phosphorescence quenching could be observed, especially at the top and bottom of the pellet, where the stress is concentrated. The MQ area of the pellet could be easily recognized with the increasing of the load from 0 to $1000 \mathrm{~N}$.

To gain more insight into the MQ mechanism of CaZnOS: $\mathrm{Cu}$, we measured the phosphorescence intensity $I($ load $)$ and $I(0)$ for different decay times ( 3 and $20 \mathrm{~min}$ and 1, 3, and $12 \mathrm{~h}$ ) under a compressive load, as shown in Figure 6. When the decay time was $3 \mathrm{~min}$ (Figure 6a), the phosphorescence intensity $I$ (load) decreased rapidly after the load was applied, which indicated that MQ occurred. Interestingly, with an increase in decay time, the decreasing $I$ (load) curve began to increase when the load was applied and then decreased below $I(0)$ after the load was removed (Figure $6 \mathrm{~b}-6 \mathrm{~d}$ ). This change suggests that the contribution of the MQ process becomes weaker, thus making the role of ML more prominent as the decay time is lengthened. We believe that this phenomenon could be explained by the combination of the MQ process and the ML process and that the dominant process depends on the decay time. In addition, after the load is reduced from 1000 to $0 \mathrm{~N}$ in Figure $6 \mathrm{~b}-6 \mathrm{~d}$, the $I$ (load) shows an secondary increase and finally coincides with $I(0)$ after approximately $90 \mathrm{~s}$ in the experiment. When the decay time is extended to $12 \mathrm{~h}$ (Figure 6e), the MQ curve almost disappears, and only the ML intensity remains.

Figure 7 shows the thermoluminescence curves of the CZOSC sample acquired after different decay times, corresponding to Figure 6. The thermoluminescence curves consist of two broad bands with maxima at 75 and $160{ }^{\circ} \mathrm{C}$, which correspond to the shallow and deep traps, respectively. The trap depths calculated by the Hoogenstraaten method were $0.42 \mathrm{eV}$ for the shallow traps and $0.71 \mathrm{eV}$ for the deep traps. In the short decay time $(3 \mathrm{~min})$, the thermoluminescence intensities for the shallow and deep traps were almost equivalent. However, as the decay time increased, the shallow-trap band was attenuated. For a decay time of $12 \mathrm{~h}$ (red curve in Figure 7), the shallow-trap band almost completely disappeared; consequently, only the deep-trap band was observed. This finding indicates that the shallow traps are responsible for the MQ and that the deep traps are responsible for the ML. This is an important clue for elucidating the mechano-optical conversions of CZOSC. 

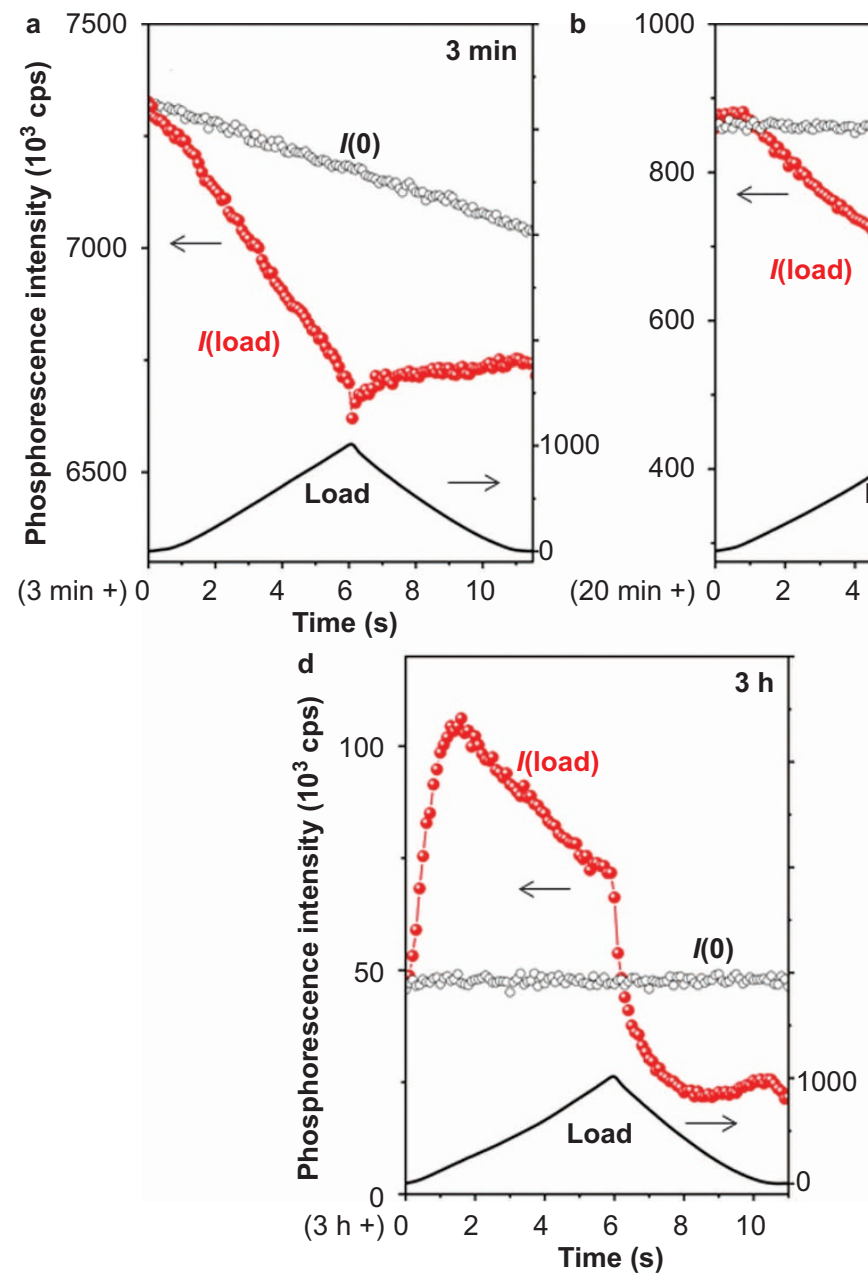
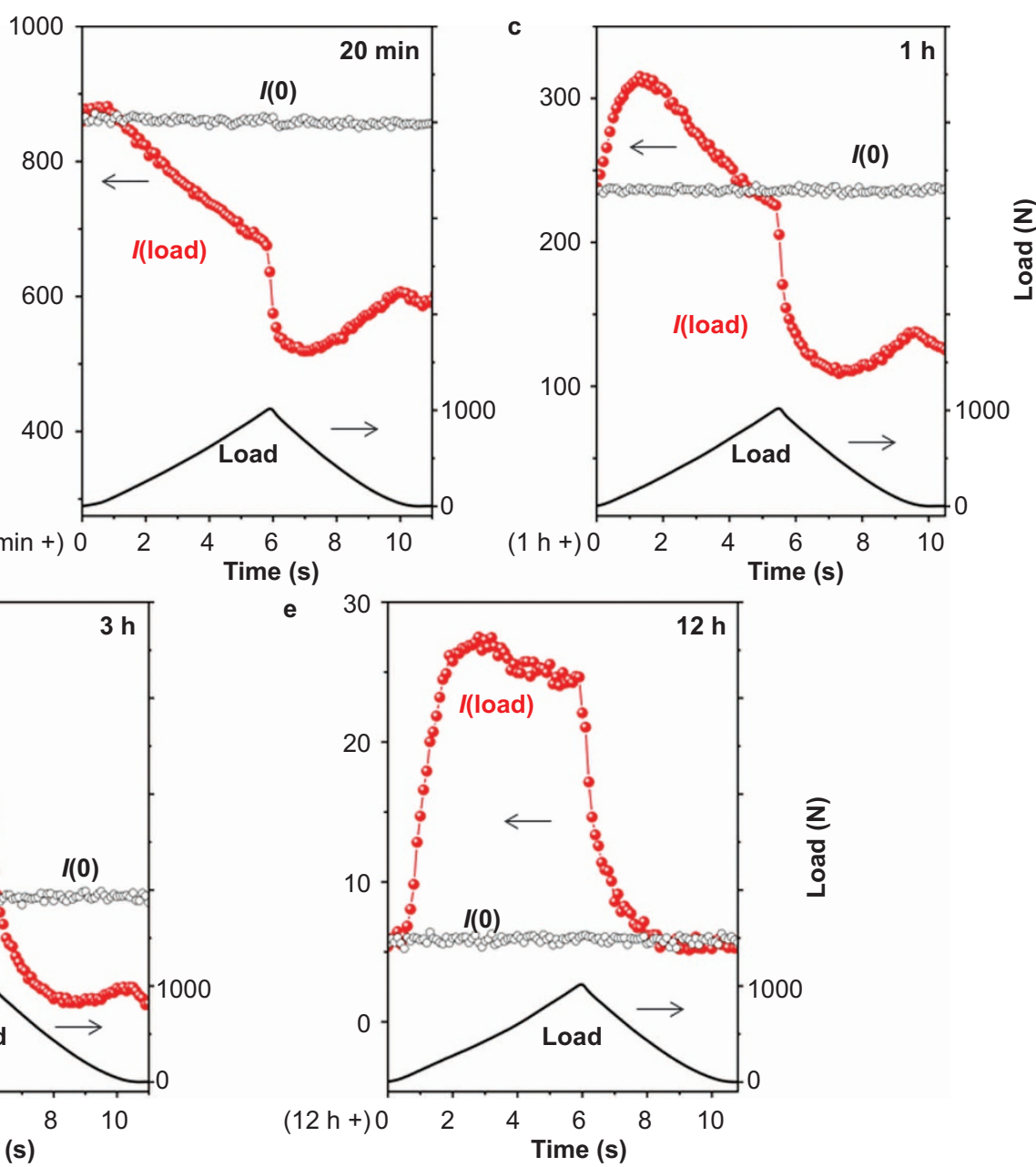

Figure 6 Phosphorescence curves, $/(\mathrm{load})$ and $/(0)$, monitored at $472 \mathrm{~nm}$ at decay times of 3, $20 \mathrm{~min}$ and $1,3,12 \mathrm{~h}$.

Based on the experimental results and discussion, we propose a mechanism for the phosphorescence, MQ and ML in CaZnOS:Cu, as shown in Figure 8. Similar to the $\mathrm{ZnS}: \mathrm{Cu}$ system ${ }^{34}$, there are two types of electron traps around $\mathrm{Cu}^{+}$in CaZnOS:Cu: nearby traps (close to $\mathrm{Cu}^{+}$) and remote traps (far from $\mathrm{Cu}^{+}$). For convenience, we refer to the remote shallow and deep traps in the MQ and ML processes as Trap1 and Trap-2, respectively. As shown in Figure 8a, under UV light (365 $\mathrm{nm}$ ) excitation, the electrons of the $\mathrm{Cu}^{+}$ions are photoionized to the conduction band (process 1) and become captured in the remote trap levels (process 2). In the phosphorescence process, the trapped electrons can be thermally released to the conduction band and are then transferred to the nearby traps via a nonradiative relaxation (process 3 ). Then, D-A recombination occurs from nearby trap levels to the $\mathrm{Cu}^{2+}$ energy state, which leads to phosphorescence (process 4).

In addition, the cation defects $\left(\mathrm{V}_{\mathrm{Zn}}\right)$ generated by $\mathrm{Cu}^{+}$doping could act as a deep-level defect and a nonradiative center in CaZnOS: $\mathrm{Cu}^{35,36}$. As shown in Figure 8 b, in the initial stage of the phosphorescence process, a local piezoelectric field can be produced when a mechanical load is applied to CaZnOS: $\mathrm{Cu}$, which causes band bending and triggers the release of many electrons captured in Trap-1 toward the nonradiative centers ${ }^{37}$. The released electrons may be excited to these nonradiative centers (process 5), and the electrons and holes recombine nonradiatively via these centers, which results in MQ. The weak ML caused by Trap-2 can be neglected. Several hours later, the release of electrons through the conduction band is decreased by the depletion of Trap-1. When the load is applied, the released electrons are excited to the conduction band (process 6$)^{38}$, and the

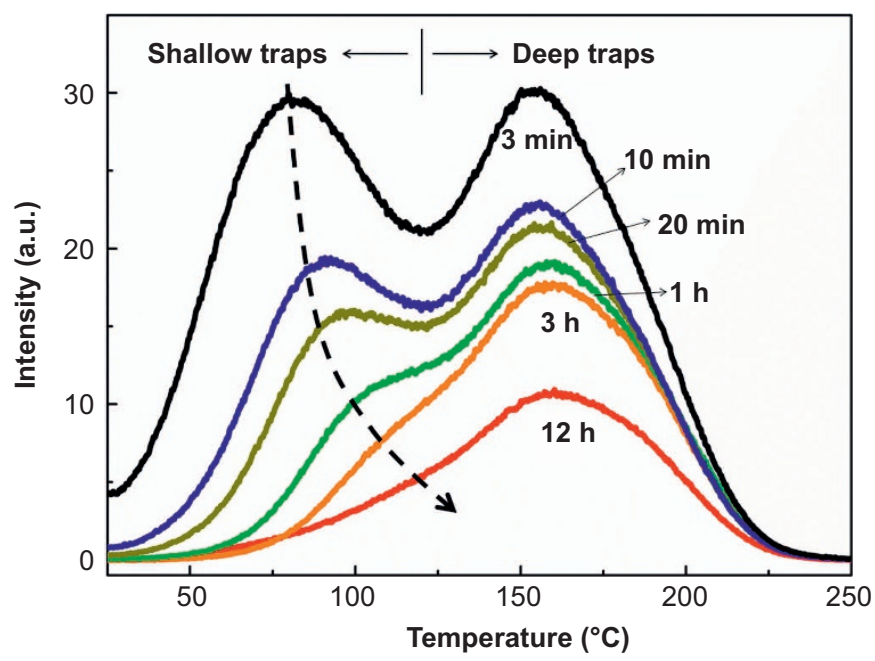

Figure 7 Thermoluminescence curves at different decay times $(3,10,20$ min and $1,3,12 \mathrm{~h}$ ) monitored at $472 \mathrm{~nm}$ from 25 to $250^{\circ} \mathrm{C}$. 
a

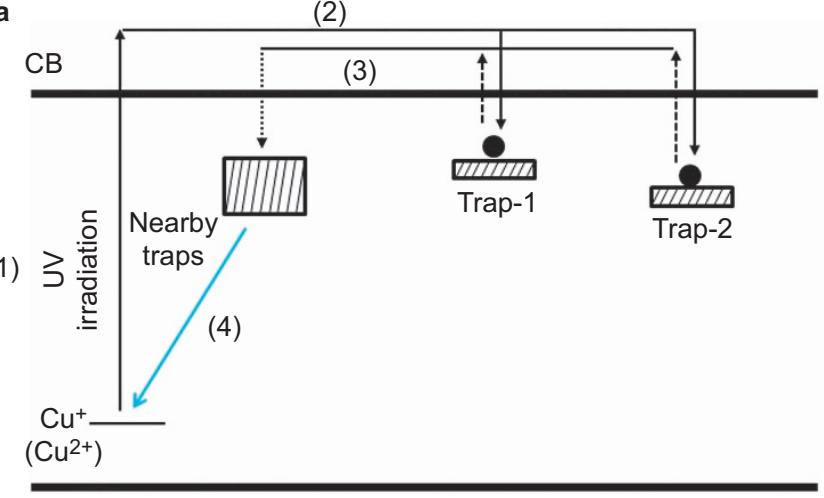

VB b

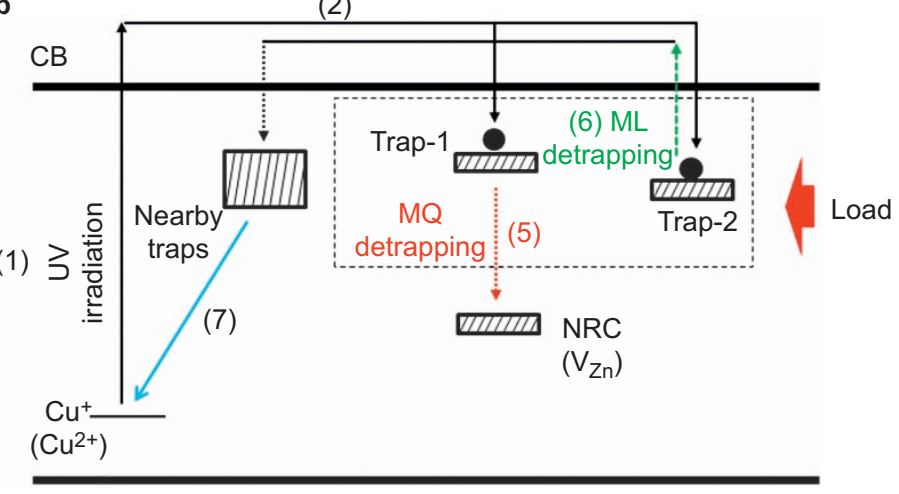

Figure 8 Schematic diagram of the mechanisms for (a) phosphorescence and (b) MQ and ML in CaZnOS:Cu.

ML process starts primarily from Trap-2 via D-A recombination, giving rise to relatively weak ML (process 7 ). This scheme could explain why the MQ changed to ML over time.

\section{CONCLUSIONS}

In summary, we have synthesized a series of CaZnOS:Cu phosphors with a hexagonal-layered structure. The amount of $\mathrm{Cu}$-doping does not affect the crystal structure of the samples. The CaZnOS:Cu emits phosphorescence after the removal of the excitation. The MQ of CaZnOS: $\mathrm{Cu}$ occurs under compressive loads. As the decay time increases, the MQ gradually swaps over to ML under a compressive load. We proposed a mechanism based on the different roles of shallow and deep traps. When the load is applied, the trapped electrons could be excited to the nonradiative centers and conduction band, which may correspond to the MQ and ML, respectively. We believe that this novel material, $\mathrm{CaZnOS}: \mathrm{Cu}$, is promising for mechanooptical sensing and that it may be suitable for many technologically important applications, especially stress sensors.

\section{ACKNOWLEDGEMENTS}

This work was partly supported by a Grant-in-Aid for Scientific Research (A) (Grant number: 25249100) from the Japan Society for the Promotion of Science. The authors thank all of their colleagues at the National Institute of Advanced Industrial Science and Technology (AIST) for technical support, especially Nao Terasaki, Yujin Terasawa, Masayoshi Fujihara, Etsuko Kawasaki, Sunao Kamimura and Dengfeng Peng for their assistance in the experiments and data analysis.

1 Xu CN, Watanabe T, Akiyama M, Zheng XG. Direct view of stress distribution in solid by mechanoluminescence. Appl Phys Lett 1999; 74: 2414-2416.

2 Dou CD, Han L, Zhao SS, Zhang HY, Wang Y. Multi-stimuli-responsive fluorescence switching of a donor-acceptor $\pi$-conjugated compound. J Phys Chem Lett 2011; 2: 666-670.

3 Mutai T, Satou H, Araki K. Reproducible on-off switching of solid-state luminescence by controlling molecular packing through heat-mode interconversion. Nat Mater 2005; 4: 685-687.

4 Sagara $Y$, Kato T. Mechanically induced luminescence changes in molecular assemblies. Nat Chem 2009; 1: 605-610.

5 Gao YF, Cheng MJ, Wang BL, Feng ZG, Shi F. Diving-surfacing cycle within a stimulusresponsive smart device towards developing functionally cooperating systems. Adv Mater 2010; 22: 5125-5128.

6 Xu CN, Yamada H, Wang XS, Zheng XG. Strong elasticoluminescence from monoclinic-structure $\mathrm{SrAl}_{2} \mathrm{O}_{4}$. Appl Phys Lett 2004; 84: 3040-3042.

7 Yan DP, Lu J, Ma J, Qin SH, Wei M et al. Layered host-guest materials with reversible piezochromic luminescence. Angew Chem Int Ed 2011: 50: 7037-7040.

8 Zhang JF, MacDonald KF, Zheludev NI. Nonlinear dielectric optomechanical metamaterials. Light Sci App/ 2013; 2: e96, doi:10.1038/sa.2013.52.
9 Terasaki N, Zhang HW, Yamada H, Xu CN. Mechanoluminescent light source for a fluorescent probe molecule. Chem Commun 2011; 47: 8034-8036.

10 Caruso MM, Davis DA, Shen QL, Odom SA, Sottos NR et al. Mechanically-induced chemical changes in polymeric materials. Chem Rev 2009; 109: 5755-5798.

11 Weder C. Mechanochemistry: polymers react to stress. Nature 2009; 459: 45-46.

12 Zhan TZ, Xu CN, Fukuda O, Yamada H, Li CS. Direct visualization of ultrasonic power distribution using mechanoluminescent film. Ultrason Sonochem 2011; 18: 436-439.

13 Wang X, Xu CN, Yamada H, Nishikubo K, Zheng XG. Electro-mechano-optical conversions in $\mathrm{Pr}^{3+}$-doped $\mathrm{BaTiO}_{3}-\mathrm{CaTiO}_{3}$ ceramics. Adv Mater 2005; 17: $1254-$ 1258.

14 Chandra VK, Chandra BP. Dynamics of the mechanoluminescence induced by elastic deformation of persistent luminescent crystals. J Lumin 2012; 132: 858-869.

15 Chandra BP. Mechanoluminescence and high pressure photoluminescence of (Zn, Cd) S phosphors. Pramana 1982; 19: 455-465.

16 Jeong SM, Song S, Lee SK, Ha NY. Color manipulation of mechanoluminescence from stress-activated composite films. Adv Mater 2013; 25: 6194-6200.

17 Zhang L, Yamada H, Imai Y, Xu CN. Observation of elasticoluminescence from $\mathrm{CaAl}_{2} \mathrm{Si}_{2} \mathrm{O}_{8}: \mathrm{Eu}^{2+}$ and its water resistance behavior. J Electrochem Soc 2008; 155: J63-J65.

18 Kamimura S, Yamada H, Xu CN. Development of new elasticoluminescent material $\mathrm{SrMg}_{2}\left(\mathrm{PO}_{4}\right)_{2}$ : Eu. J Lumin 2012; 132: 526-530.

19 Rahimi MR, Yun GJ, Doll GL, Choi JS. Effects of persistent luminescence decay on mechanoluminescence phenomena of $\mathrm{SrAl}_{2} \mathrm{O}_{4}: \mathrm{Eu}^{2+}$, Dy ${ }^{3+}$ materials. Opt Lett2013; 38: 4134-4137.

20 Timilsina S, Lee KH, Jang IY, Kim JS. Mechanoluminescent determination of the mode I stress intensity factor in $\mathrm{SrAl}_{2} \mathrm{O}_{4}: \mathrm{Eu}^{2+}, \mathrm{Dy}^{3+}$. Acta Mater 2013; 61: 7197-7206.

21 Botterman J, van den Eeckhout K, de Baere I, Poelman D, Smet PF. Mechanoluminescence in $\mathrm{BaSi}_{2} \mathrm{O}_{2} \mathrm{~N}_{2}$ : Eu. Acta Mater 2012; 60: 5494-5500.

22 Zhang L, Xu CN, Yamada H. Strong mechanoluminescence from oxynitridosilicate phosphors. IOP Conf Ser: Mater Sci Eng 2011; 18: 212001.

23 Zhang JC, Xu CN, Kamimura S, Terasawa Y, Yamada H et al. An intense elasticomechanoluminescence material CaZnOS: $\mathrm{Mn}^{2+}$ for sensing and imaging multiple mechanical stresses. Opt Express 2013; 21: 12976-12986.

$24 \mathrm{Tu}$ D, Xu CN, Fujio Y. Intense red emitting mechanoluminescence from CaZnOS: Mn, Li with c-axis preferred orientation. J Adv Dielect 2014; 4: 1450017.

25 Kamimura S, Yamada H, Xu CN. Strong reddish-orange light emission from stressactivated $\mathrm{Sr}_{n+1} \mathrm{Sn}_{n} \mathrm{O}_{3 n+1}: \mathrm{Sm}^{3+}(\mathrm{n}=1,2, \infty)$ with perovskite-related structures. Appl Phys Lett 2012; 101: 091113

26 Tu D, Xu CN, Fujio Y, Kamimura S, Sakata Y et al. Phosphorescence quenching by mechanical stimulus in CaZnOS: Cu. Appl Phys Lett 2014; 105: 011908.

27 Sambrook T, Smura CF, Clarke SJ. Structure and physical properties of the polar oxysulfide CaZnOS. Inorg Chem 2007; 46: 2571-2574.

28 Yang WJ, Chen TM. White-light generation and energy transfer in $\mathrm{SrZn}_{2}\left(\mathrm{PO}_{4}\right)_{2}: \mathrm{Eu}, \mathrm{Mn}$ phosphor for ultraviolet light-emitting diodes. Appl Phys Lett 2006; 88: 101903.

29 Shi YR, Wen Y, Que MD, Zhu G, Wang YH. Structure, photoluminescent and cathodoluminescent properties of a rare-earth free red emitting $\beta-\mathrm{Zn}_{3} \mathrm{~B}_{2} \mathrm{O}_{6}: \mathrm{Mn}^{2+}$ phosphor. Dalton Trans 2014; 43: 2418-2423.

30 Tian YF, Li YF, He M, Putra IA, Peng HY et al. Bound magnetic polarons and $p$-d exchange interaction in ferromagnetic insulating Cu-doped $\mathrm{ZnO}$. Appl Phys Lett 2011: 98: 162503 .

31 Miwa K, Ohba N, Towata S, Nakamori Y, Orimo S. First-principles study on coppersubstituted lithium borohydride, $\left(\mathrm{Li}_{1-x} \mathrm{Cu}_{x}\right) \mathrm{BH}_{4}$. J Alloys Comp 2005; 404-406: 140-143.

32 Zhang BH, Xu XH, Li QY, Wu YM, Qiu JB et al. Long persistent and optically stimulated luminescence behaviors of calcium aluminates with different trap filling processes. J Solid State Chem 2014; 127: 136-141.

33 Shinoya S, Yen WM. Phosphor Handbook. Boca Raton, FL: CRC Press; 1998; Chapter 3: pp. 242-250. 
34 Clabau F, Rocquefelte X, Le Mercier T, Deniard P, Jobic S et al. Formulation of phosphorescence mechanisms in inorganic solids based on a new model of defect conglomeration. Chem Mater 2006; 18: 3212-3220.

35 Rubel O, Baranovskii SD, Hantke K, Kunert B, Ruhle WW et al. Model of temperature quenching of photoluminescence in disordered semiconductors and comparison to experiment. Phys Rev B 2006; 73: 233201.

36 Stoneham AM. Non-radiative transitions in semiconductors. Rep Prog Phys 1981; 44 1251-1295.

37 Xu CN, Matsui H, Liu Y, Zheng XG, Li LY. Novel approach to dynamic imaging of stress distribution with piezoluminescence. Ferroelectrics 2001; 263: 3-8.
38 Chandra BP, Chandra VK, Jha P. Piezoelectrically-induced trap-depth reduction model of elastico-mechanoluminescent materials. Phys B 2015; 461: 38-48.

cc) (i) $\Theta$ This work is licensed under a Creative Commons Attribution-NonCommercial( article are included in the article's Creative Commons license, unless indicated otherwise in the credit line; if the material is not included under the Creative Commons license, users will need to obtain permission from the license holder to reproduce the material. To view a copy of this license, visit http://creativecommons.org/licenses/by-nc-nd/4.0/

Supplementary information for this article can be found on the Light: Science \& Applications' website (http://www.nature.com/lsa/). 